\title{
Extraordinary Tumor Growth Rates in Bilateral Meningioma-Vestibular Schwannoma Collision Tumors in a Patient with Neurofibromatosis Type 2: Case Report and Literature Review
}

\author{
Sasan Darius Adib ${ }^{1}$ (D) Rocio Evangelista Zamora ${ }^{1} \cdot$ Marcos Tatagiba $^{1}$
}

Accepted: 28 October 2020/Published online: 4 November 2020

(C) The Author(s) 2020

\begin{abstract}
Collision tumors seem to be an extraordinary pathology with unusual features. We sought to report the management of very fastgrowing bilateral meningioma-vestibular schwannoma collision tumors in a patient with neurofibromatosis type 2 . Both meningiomas and both vestibular schwannoma, when analyzed by volumetry, showed a very rapid growth rate $\left(0.476-0.833 \mathrm{~cm}^{3}\right.$ per month) in comparison with two meningiomas of other locations $\left(0.132-0.233 \mathrm{~cm}^{3}\right.$ per month). To the best of our knowledge, the growth rates of both vestibular schwannomas in the present case are the fastest that have been described in literature for a vestibular schwannoma so far.
\end{abstract}

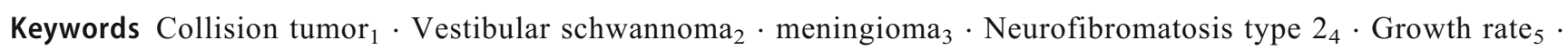
Cerebellopontine angle 6

\section{Background}

Collision tumors of the cerebellopontine angle (CPA), which are defined by Frassanito et al. [5] as histologically distinct tumors, arising at different topographical sites, growing simultaneously, and intermingling each other, are a rare phenomemon [5]. They seem to be an extraordinary pathology with unusual fast growth rate [13].

In a previous study, we described the surgical management of collision tumors between vestibular schwannoma and

This article is part of the Topical Collection on Surgery

Details of previous presentations of portions of this research:

1. Previous presentation:

Name of the annual meeting: 67th Annual Meeting of the German Society of Neurosurgery (DGNC)

Sponsoring society: No sponsoring society

Date: 12-15 June 2016

Location: Frankfurt, Germany

Presentation type: Oral presentation

Sasan Darius Adib

sasan_adib2002@yahoo.de

1 Department of Neurosurgery, University of Tuebingen, Hoppe-Seyler-Straße 3, 72076 Tuebingen, Germany meningioma in the cerebellopontine angle in patients with neurofibromatosis type 2 [1].

Out of these groups of patients, one case was very well radiologically documented (with four MRI of the head within 1 year).

We sought to report the extraordinary tumor growth rates in bilateral meningioma-vestibular schwannoma collision tumors in a patient with neurofibromatosis type 2 .

\section{Case Presentation}

A 26-year-old woman presenting with a 1-year history of progressive loss of hearing and bilateral visual impairment with dramatically worsening during pregnancy (nearly deaf) underwent magnetic resonance imaging (MRI) of the brain 3 months after the birth of her healthy child. MRI revealed multiple intracranial lesions comprising two tumors of both CPAs, which were in contact with each other and exhibited two continuous, differently enhancing components following gadolinium administration. The radiological features of the lesion suggested a collision tumor of VS and meningioma (Fig. 1a) with intermingling zone (Fig. 1b) on both sides. MRI of the spine revealed multiple spinal lesions, including intramedullary and spinal nerve lesions. A review of the patient's family history revealed no evidence of NF 2 . 


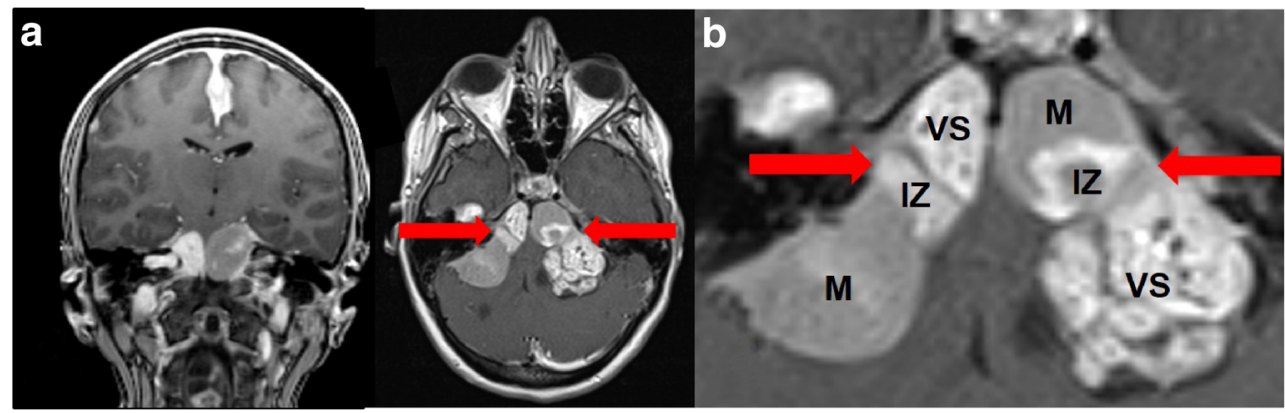

Fig. 1 a "Kissing tumors": collision between a vestibular schwannomapetroclival meningioma collision tumor of the left CPA and a vestibular schwannoma-petrosal meningioma collision tumor of the right CPA in

According to the Manchester criteria (1997), the diagnosis of NF 2 was established.

\section{Intervention}

The patient underwent three surgical procedures. The first surgical procedure consisted of removal of the collision tumors of the left CPA via a retrosigmoid approach with facial nerve reconstruction (Fig. 2a-c). Histopathological findings confirmed the diagnosis of a collision between a schwannoma and a meningioma with different portions of meningotheliomatous (WHO I, MIB1 $=2 \%$ ) and atypical (WHO II, MIB1 = 5\%) types. Postoperative MRI scan demonstrated total excision of the collision tumors of the left CPA.

The second surgical procedure consisted of decompression of the optic canal due to of rapid deterioration of the visual function due to a meningioma of the optic canal. The vision in the left eye gradually improved. Histopathological examination confirmed coronal and axial MRI. b Intermingling zones of both collision tumors (VS, vestibular schwannoma; IZ, intermingling zone; M, meningioma)

the diagnosis of a meningotheliomatous meningioma (WHO I, MIB1 $=1 \%$ ).

The third surgical procedure consisted of a subtotal removal of the collision tumor of the right CPA with preservation of the facial nerve, and placement of an auditory brain stem implant (ABI) (Fig. 2d-e). Histopathological findings confirmed the diagnosis of a collision tumor between a schwannoma and a meningioma (WHO I, MIB1 = 3\%) (with transitional and psammomatous components and a positive progesterone receptor status).

\section{Postoperative Course}

Follow-up examination showed improvement of left facial function to HB grade III. The patient experienced auditory sensation following ABI placement. The vision in the left eye improved to a level almost similar to that before surgery. The postoperative MRI scan demonstrated nearly total excision of the collision tumors of the right CPA.

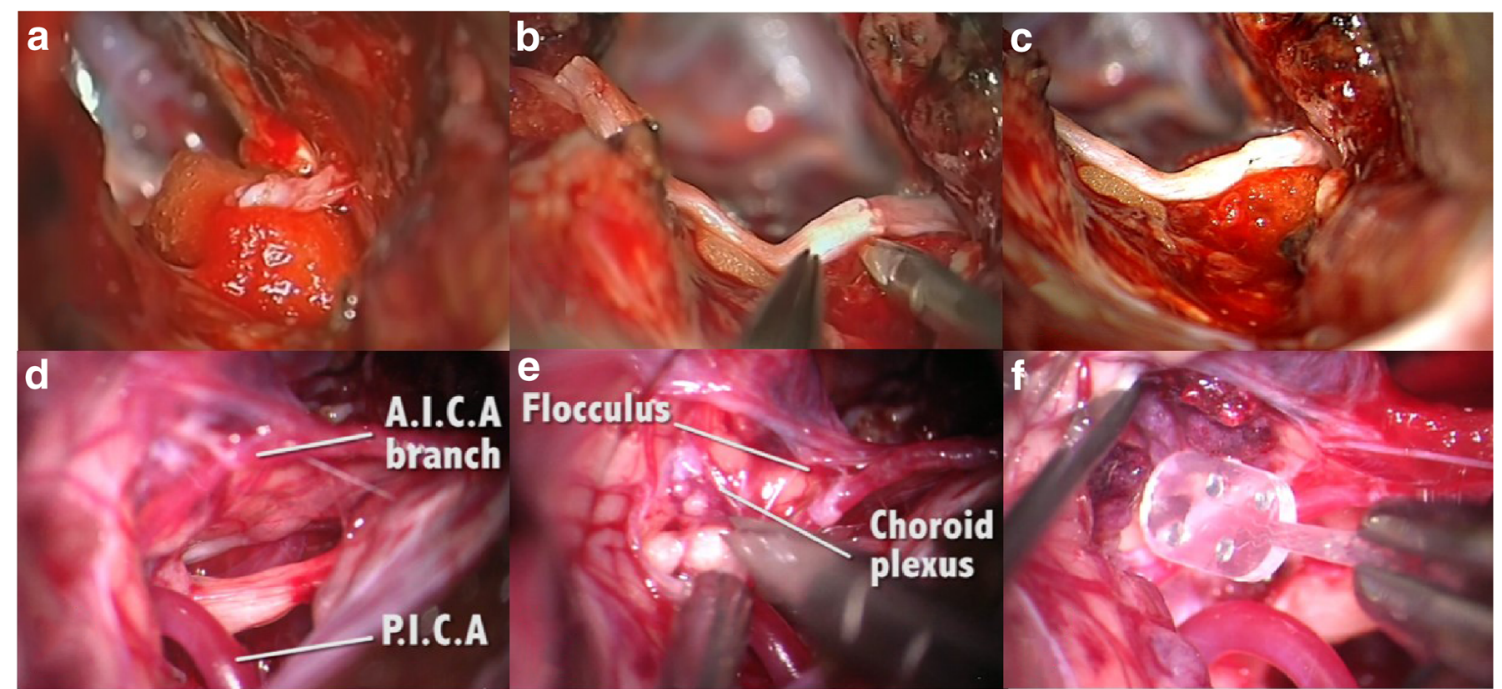

Fig. 2 a-c Facial nerve reconstruction using an end-to-end interposed sural nerve graft $(\mathbf{a}, \mathbf{b}, \mathbf{c})$. $\mathbf{d}-\mathbf{f}$ Placement of an $\mathrm{ABI}$ : identification of the anatomic landmarks, including A.I.C.A. and P.I.C.A. (d) and flocculus and choroid plexus (e). An electrode array was placed into the lateral recess on the posterior surface of the brain stem (f) 


\section{Genetic Analysis}

A heterozygous nonsense mutation was identified in the genetic analysis.

\section{Volumetry}

For volumetric analyses, MRI scans (from June 2014, September 2014, January 2015, May 2015) were transmitted to iplan 7 (brainlab®) (Table 1). Both vestibular schwannomas and both meningiomas of the collision tumor were contoured manually on each slice in the T1-weighted postgadolinium images. Both meningiomas and both VS, when analyzed by volumetry, exhibited an extremely rapid growth rate of $0.476-0.833 \mathrm{~cm}^{3}$ per month and an annual growth rate of 5706-9995 $\mathrm{cm}^{3}$ (Table 2). We also performed volumetry of the meningioma of the optic canal and of a falcine meningioma, which demonstrated a growth rate of $0.132-0.233 \mathrm{~cm}^{3}$ per month and an annual growth rate of $1583-2792 \mathrm{~cm}^{3}$.

\section{Discussion}

\section{Collision Tumors of CPA}

Cushing and Eisenhardt [3] were one of the first to describe combined neurinomas and meningiomas in the same patient [9], and Davidoff and Martin [4] reported two cases of neurinomas with combined meningiomatosis.

Similar to Meyer [12], Frassanito et al. [5] defined different constellations of two different tumors (concomitant, contiguous, and collision tumors) in the same patient and distinguished their pathologies from those of "mixed tumors." Graffeo et al. emphasized a different classification [6].

In collision tumors, an autocrine-paracrine growth-stimulatory mechanism may act as a stimulus for the development of an adjacent tumor $[5,10,13,16]$. Pallini et al. [13] described a NF2 patient with bilateral VS and a parasellar meningioma in whom the parasellar meningioma infiltrated the tentorium and approached the ipsilateral schwannoma [13], resulting in the development of a collision tumor. Thereafter, the percentage of the annual growth rate of ipsilateral VS increased by a factor of approximately 10 [2]. They identified epidermal growth factor as one of the possible factors for the stimulation of the tumor growth [13].

\section{Growth Rate and Growth Pattern}

In 2016, Picry et al. [15] reported that the long-term annual volumetric growth rate of VS in NF2 is $0.2183 \mathrm{~cm}^{3} /$ year (range: -0.01 to $1.250 \mathrm{~cm}^{3} /$ year). The highest growth rate was found in cases with constitutional nonsense mutations $\left(0.33694 \mathrm{~cm}^{3} /\right.$ year $)$, and the lowest growth rate was seen in cases with mosaic frame shift mutations $\left(0.10214 \mathrm{~cm}^{3} /\right.$ year $)$ [15]. Harris et al. [7] presented different results, however. In their study, the annual volumetric growth rate was $0.7 \pm$ $1.4 \mathrm{~cm}^{3} /$ year (range: -0.1 to $4.4 \mathrm{~cm}^{3} /$ year).

In our case, the annual growth rate was even several times higher than that observed in the constitutional nonsense mutation group in the study of Picry et al. [15] and the volumetric growth rate reported by Harris et al. [7] The growth rate per year for the right VS was $8.326 \mathrm{~cm}^{3}$ (June 2014-May 2015), and that for the left VS was $7506 \mathrm{~cm}^{3}$ (projected from the tumor growth rate between June 2014 and September 2014) (Table 2).

Different growth patterns of intracranial tumors in patients with NF2 have been described in the literature [11]. Although the majority of intracranial tumors in case of NF2 exhibit a saltatory growth in the volumetric measurements, a linear and exponential growth pattern has also been described [11].

The single tumors of both collision tumors in our patient demonstrated a linear growth pattern.

\section{Proliferation Activity}

MIB1 labeling indices were analyzed to compare the proliferative activity between the meningiomas of the collision tumors and the meningioma of the anterior skull base (Table 2). MIB1 labeling indices were higher in the meningiomas of the left $(2 \%$

Table 1 Volume of meningioma and vestibular schwannoma $\left(\mathrm{cm}^{3}\right)$

\begin{tabular}{lllll}
\hline Volume & Date of MRI & & \\
\cline { 2 - 5 } & June 2014 & September 2014 & January 2015 & May 2015 \\
\hline Right VS & 6.647 & 8.174 & 12.262 & 14.973 \\
Right meningioma & 9.084 & 12.093 & 14.011 & 19.079 \\
Left VS & 25.384 & 27.886 & 1.29 & 1.72 \\
Left meningioma & 9.275 & 11.177 & 0 & 0 \\
\hline
\end{tabular}

Red data, early recurrence of the vestibular schwannoma/DD schwannoma of another lower cranial nerve; $V S$ vestibular schwannoma 
Table 2 Initial volume, mean monthly and annual growth rate $\left(\mathrm{cm}^{3}\right)$, WHO grade, and MIB1 of the different tumors

\begin{tabular}{|c|c|c|c|c|c|c|}
\hline & Right VS & Right $\mathrm{M}$ & Left VS & Left M & Opt. M & Falcine M \\
\hline Initial volume $\left(\mathrm{cm}^{3}\right)$ first MRI & 6.647 & 9.084 & 25.384 & 9.275 & 10.764 & 7.655 \\
\hline Mean volume growth $\left(\mathrm{cm}^{3}\right)$ per month & 0.694 & 0.833 & 0.626 & 0.476 & 0.233 & 0.132 \\
\hline Mean volume growth $\left(\mathrm{cm}^{3}\right)$ per year & 8.326 & 9.995 & 7.506 & 5.706 & 2.792 & 1.583 \\
\hline WHO grade & I & I & I & $\mathrm{I}+\mathrm{II}$ & I & Not removed \\
\hline MIB1 & $3 \%$ & $3 \%$ & $1-2 \%$ & $5 \%$ & $1 \%$ & Not removed \\
\hline
\end{tabular}

$M$ meningioma, Opt. $M$ meningioma of the optic canal, $V S$ vestibular schwannoma

and 5\%) and the right (3\%) collision tumor than in the meningioma of the optic canal (1\%).

The MIB1 labeling index of the right VS was 3\%, and that of the left VS was 1-2\% (Table 2).

\section{Growth Rate and Pregnancy}

Harvey Cushing [2] was the first person who described the increased growing tendency of VS during pregnancy in 1917.

Because of the fact that VS contain estrogen receptors, it has been hypothesized that estrogen plays an important role in the acceleration of symptoms [14].

Kasantikul et al. [8] described that the "direct hormonal effect of tumor growth" was dependent on the progesterone receptor and the estrogen receptor.

If pregnancy would be the only factor responsible for the rapid tumor growth rate in our case, we would expect the growth rates and the MIB1 of the meningiomas of the collision tumors to be similar to those of the meningiomas of other locations, which are not.

The mean volume growth per year of the right $\left(9.995 \mathrm{~cm}^{3}\right)$ and the left $\left(5.706 \mathrm{~cm}^{3}\right)$ meningioma of the collision tumors was much higher than that of the meningioma of the anterior skull base $\left(2.792 \mathrm{~cm}^{3}\right)$ and that of the falcine meningioma $\left(1.583 \mathrm{~cm}^{3}\right)$.

The percentage volume growth per year (compared to the tumor volume in the initial MRI in June 2014) was also much higher (meningioma of the right collision tumor $110 \%$, meningioma of the left collision tumor $62 \%$, meningioma of the optic canal $26 \%$, falcine meningioma $21 \%$ ).

\section{Conclusion}

We hypothesized that in addition to NF2 (and the type of mutation) and pregnancy, an interrelated stimulation of the collision tumors might explain the rapid tumor growth rate observed in our case.

In summary, the following three findings support our hypothesis:
1 To the best of our knowledge, the growth rates of both vestibular schwannomas $\left(8.326 \mathrm{~cm}^{3} /\right.$ year and $7.506 \mathrm{~cm}^{3} /$ year) in the present case are the fastest that have been described in the literature for a VS till date (even 10 times faster than that described for a nonsense mutation in case of NF2 by Picry et al. [15])

2 The MIB1 of the meningiomas of both meningioma and VS collision tumors was higher than that of the meningioma of the optic canal.

3 The growth rates of both meningiomas in both collision tumors were higher than those of the meningiomas of other locations (optic canal and falx).

Nevertheless, this effect that was detected in our case and by Pallini et al. [13] has to be analyzed in further studies.

Authors' Contributions SDA performed the analyses, wrote the manuscript, and performed critical revision; REZ performed analyses and performed critical revision; MT performed analyses and performed critical revision.

Funding Open Access funding enabled and organized by Projekt DEAL.

Data Availability All data are included in the manuscript.

\section{Compliance with Ethical Standards}

Conflict of Interest The authors declare that they have no conflict of interest.

Ethical Approval This case report was performed in accordance with the ethical standards of the institutional research committee (University of Tuebingen/ethic commission) and with the 1964 Helsinki declaration and its later amendments or comparable ethical standards.

Consent to Participate Informed consent was obtained from the patient.

Consent for Publication Informed consent was obtained from the patient.

Code Availability Not applicable.

Open Access This article is licensed under a Creative Commons Attribution 4.0 International License, which permits use, sharing, adaptation, distribution and reproduction in any medium or format, as long as you give appropriate credit to the original author(s) and the source, 
provide a link to the Creative Commons licence, and indicate if changes were made. The images or other third party material in this article are included in the article's Creative Commons licence, unless indicated otherwise in a credit line to the material. If material is not included in the article's Creative Commons licence and your intended use is not permitted by statutory regulation or exceeds the permitted use, you will need to obtain permission directly from the copyright holder. To view a copy of this licence, visit http://creativecommons.org/licenses/by/4.0/.

\section{References}

1. Adib SD, Tatagiba M. Surgical management of collision-tumors between vestibular schwannoma and meningioma in the cerebellopontine angle in patients with neurofibromatosis type 2 . Acta Neurochir. 2019;161(6):1157-63.

2. Cushing H. Tumors of the nervus acusticus and the syndrome of the cerebellopontine angle. Philadelphia: WB Saunders; 1917.

3. Cushing H, Eisenhardt L. Meningiomas. New York: Hafner; 1938. p. $100-114$ p.

4. Davidoff LM, Martin J. Hereditary combined neurinomas and meningiomas. J Neurosurg. 1955;12(4):375-84.

5. Frassanito P, Montano N, Lauretti L, Pallini R, Fernandez E, Lauriola L, et al. Simultaneously occurring tumours within the same cerebello-pontine angle: refining literature definitions and proposal for classification. Acta Neurochir. 2011;153(10):198993 discussion 1993.

6. Graffeo CS, Perry A, Copeland WR, Giannini C, Neff BA, Driscoll CLW, et al. Synchronous tumors of the cerebellopontine angle. World Neurosurg. 2017;98:632-43.

7. Harris GJ, Plotkin SR, Maccollin M, Bhat S, Urban T, Lev MH, et al. Three-dimensional volumetrics for tracking vestibular schwannoma growth in neurofibromatosis type II. Neurosurgery. 2008;62(6):1314-9 discussion 1319-1320.
8. Kasantikul V, Netsky MG, Glasscock ME, Hays JW. Acoustic neurilemmoma. Clinicoanatomical study of 103 patients. J Neurosurg. 1980;52(1):28-35.

9. Kim DG, Paek SH, Chi JG, Chun YK, Han DH. Mixed tumour of schwannoma and meningioma components in a patient with NF-2. Acta Neurochir. 1997;139(11):1061-4 discussion 1064-1065.

10. Kutz JW, Barnett SL, Hatanpaa KJ, Mendelsohn DB. Concurrent vestibular schwannoma and meningioma mimicking a single cerebellopontine angle tumor. Skull Base. 2009;19(6):443-6.

11. Lawson McLean AC, Rosahl SK. Growth dynamics of intracranial tumors in patients with neurofibromatosis type 2. World Neurosurg. 2017;98:152-61.

12. Meyer R. Beitrag zur Verständigung über die Namensgebung in der Geschwulstlehre. Zentralbibiothek Allgemeine Pathologie. 1919;30:291-6.

13. Pallini R, Tancredi A, Casalbore P, Mercanti D, Larocca LM, Consales A, et al. Neurofibromatosis type 2: growth stimulation of mixed acoustic schwannoma by concurrent adjacent meningioma: possible role of growth factors. Case report. J Neurosurg. 1998;89(1):149-54.

14. Patel AK, Alexander TH, Andalibi A, Ryan AF, Doherty JK. Vestibular schwannoma quantitative polymerase chain reaction expression of estrogen and progesterone receptors. Laryngoscope. 2008;118(8):1458-63.

15. Picry A, Bonne N-X, Ding J, Aboukais R, Lejeune J-P, Baroncini $\mathrm{M}$, et al. Long-term growth rate of vestibular schwannoma in neurofibromatosis 2: a volumetric consideration. Laryngoscope. 2016;126:2358-62. https://doi.org/10.1002/lary.25976.

16. Rodriguez FJ, Scheithauer BW, Fourney DR, Robinson CA. Ependymoma and intraparenchymal calcifying pseudoneoplasm of the neural axis: incidental collision or unique reactive phenomenon? Acta Neuropathol. 2008;115(3):363-6.

Publisher's Note Springer Nature remains neutral with regard to jurisdictional claims in published maps and institutional affiliations. 